\title{
Correction to: Diagnostic of Concrete Samples Affected by Internal Swelling Reactions
}

\section{Correction to:}

\author{
A. C. Azevedo et al., Diagnostic of Concrete Samples \\ Affected by Internal Swelling Reactions, \\ Building Pathology and Rehabilitation 21, \\ https://doi.org/10.1007/978-3-030-76497-5
}

In the original version of the book, the following belated corrections have been incorporated: The author name "Nicole P. S. Souza and Fernando A.N Silv" has been changed to "Nicole P.S. Nascimento" and Fernando A.N Silva" in the metadata, cover and book contents (title page, affiliation page, and Preface's signatories). 